\title{
Spinopelvic Parameters in Anterior Lumbar Interbody Fusion, the First Follow-Up Study of Three Years in Mexican Population
}

\author{
Diego Quillo-Olvera ${ }^{* 1}$, MD, Javier Quillo-Olvera ${ }^{2}$, MD, Javier Quillo-Resendiz ${ }^{2}$, MD, Alfonso Vega-Sosa ${ }^{3}$, MD \\ ${ }^{1}$ Department of Neurosurgery, The Regional Hospital "Dr Valentin Gomez Farias" ISSSTE. Guadalajara Jalisco, Mexico \\ ${ }^{2}$ Neurosurgeon, Spine Surgeon, The Brain and Spine Care Center, Minimally Invasive Spine Surgery Center, Querétaro \\ City, México \\ ${ }^{3}$ Neurosurgeon, Spine Surgeon, Department of Neurosurgery, Navy Mexican Hospital; México City \\ *Corresponding Author: Diego Quillo-Olvera, MD; drquilloolvera86@gmail.com \\ Postal Address: Doctores \# 102 colonia el Marques, Santiago de Querétaro CP 76047, Mexico
}

Received 07 May 2019;

Accepted 23 June 2019;

Published -- June 2019

\begin{abstract}
Objective: The objective of this work is to identify the modifications of the spinopelvic balance posterior to the ALIF and therefore its clinical repercussion.

Methods: A retrospective study of 20 patients were included, patients treated with ALIF was performed by 2 neurosurgeons and 1 vascular surgeon in 1 medical center in 2015, clinical data and radiographic measurements pre and postoperative at 3 years follow-up were studied.

Results: The number of patients was 20; 16 females (80\%) and 4 males (20\%), with a follow-up 36 months, the mean age of the studied group was 50.1 \pm 8.5 years (range 35-67 years), body mass index (BMI) was $29 \pm 3.5$, two of the 20 patients (10\%) had undergone prior spine surgery, a total of 26 ALIF levels were treated in 20 patients, fourteen patients (70\%) underwent 1 level L5-S1 and six patients (6\%) underwent 2 level L4-L5,L5-S1. All ALIF cages were supplemented with anterior integrated fixation, eight $(40 \%)$ of 20 patients were treated with posterior spinal fixation in addition to their ALIF procedure, Twelve (60\%) of 20 patients were standalone ALIF. The mean hospital stay after ALIF procedure were $4.05 \pm 1.87$ days (range 2-9 days).

PI, SS, PT and LL were measures pre and the postoperative was the last reported during the 3 years follow up, PI and SS has statistically significant ( $\mathrm{p}=0.008$ and 0.012 ) correspondingly. Visual analog scale (VAS) was the measure preoperative and the postoperative was the last reported getting statistically significant $(\mathrm{p}=0.001)$ and the complications obtained in 4 cases were persistent pain, bleeding, intestinal pseudoclusion and retrograde ejaculation.

Conclusions: The interaction between the anatomy of the pelvis and the paravertebral muscles have a direct influence on the stress of the intervertebral discs, improving the posture of the spine and minimizing energy expenditure.

In this work performed the changes in the espinopelvic parameters that are described in the literature were obtained; we know that the ALIF improves the pelvic incidence and therefore the lumbar lordosis postoperative. Here we could verify that the modification of spinopelvic balances is related to the clinical improvement of the patient in the follow-up after his surgery, however is necessary to demonstrate quantitatively the modification of these parameters in our population to justify that the surgery is a satisfactory result for the patient.
\end{abstract}

Keywords: spinopelvic parameters; anterior lumbar interbody fusion; pelvic incidence; lumbar lordosis.

\section{Introduction}

Historically anterior lumbar interbody fusion (ALIF) was described by Capener in $1932^{[1,2,3,4]}$ as a technique to treat spondylolisthesis having the landmark intervertebral disc space implanting bone graft to create fusion between two vertebrae for an anterior access through the abdominal cavity. Several advances was development by $1980^{\prime}$ 's to improved the procedure ${ }^{[5,6,7,8,9]}$.
The techniques of minimal invasive spine surgery are currently carried out more frequently. Multiple biomechanical and intersomatic fusion advantages have been documented in multiple studies, ranging from improving the height of the intersomatic space, indirect decompression, lumbar lordosis, reduction of listhesis and improving the coronal and sagittal balance ${ }^{[10,11,12]}$.

The advantages of anterior approach to the lumbar spine compared to other techniques as posterior lumbar interbody fusion (PLIF), Transforaminal interbody fusion (TLIF), lateral lumbar interbody 
fusion (LLIF) ${ }^{[13,14]}$, avoid perineural and epidural fibrosis, paraspinal muscles injury and their respective complications $^{[15,16,17]}$.

The importance of the restoration of sagittal spinal balance demonstrated clinical outcomes in the pain relief and function of the patient ${ }^{[18]}$, the relation of the pelvis to the spine described as spinopelvic balance and the parameters are considered like pelvic tilt (PT), sacral slope (SS), pelvic incidence(PI) and lumbar lordosis (LL) have been the alignment targets to corrected sagittal deformity ${ }^{[19-31]}$.

The pelvic incidence is determined by pelvic tilt and sacral slope which are highly correlated with lumbar lordosis ${ }^{[32-38]}$.

The lumbosacral morphology and the global sagittal balance are the main factors of the biomechanical pathogenesis of the sagittal balance disorders, consequently the mechanical tension of the lumbosacral junction translated into pain and future deformation $^{[39,40,41]}$

The objective of this work is to identify the modifications of the spinopelvic balance posterior to the ALIF and therefore its clinical repercussion.

\section{Methods}

A retrospective study of 30 patients treated with ALIF was performed by 2 neurosurgeons and 1 vascular surgeon in 1 center in 2015. The criteria inclusion were 1) patients treated with ALIF, 2) had radiographic preoperative and postoperative follow-up at an average of 3 year register. In this manner, 20 patients were included, and 10 patients were excluded due to missing radiographic data. An independent observer studied the patients, clinical data and radiographic measurements pre and postoperative.

Demographic data included age at the time of surgery, sex, body mass index, diagnosis and length of follow-up.

Operative details included a history of prior spine surgery, prior spine fusion, number of ALIF levels, anterior cage fix, posterior spinal fixation and length of hospital stay.

The comparison of the radiographic spinopelvic parameters pre and postoperative of interest were pelvic tilt (PT), sacral slope (SS), pelvic incidence (PI) and lumbar lordosis (LL) and the outcomes measures pre and postoperative included assessing visual analog scale (VAS).

Statistical analyses included frequency testing for demographic and treatment variables, paired t-tests comparing spinopelvic parameters and clinical outcomes from preoperative and postoperative. Statical analysis was carried out using SPSS v. 19.0.

\section{Surgical technique}

Under general anesthesia, the patient in supine upon operating table, we planning the abdominal approach with assistance of vascular surgeon, infraumbilical middle line $4-5 \mathrm{~cm}$ skin incision done using retroperitoneal route which is mobilized from the inner abdominal wall medially the contents of the abdominal cavity and is exposed the iliac vessels. The target area is exposed, it opens the disc space, removal of disc material and prepare the endplates for optimal placement of a cage with human bone morphogenetic protein to improve the interbody fusion, during this process we use the $\mathrm{x}$ ray control to carry out the procedure, we chose the implant and secure into the vertebral body with 4 screws through standalone mechanism. In some cases tanspedicular posterior percutaneous screws they were required for the end of the procedure (Figure 1.)

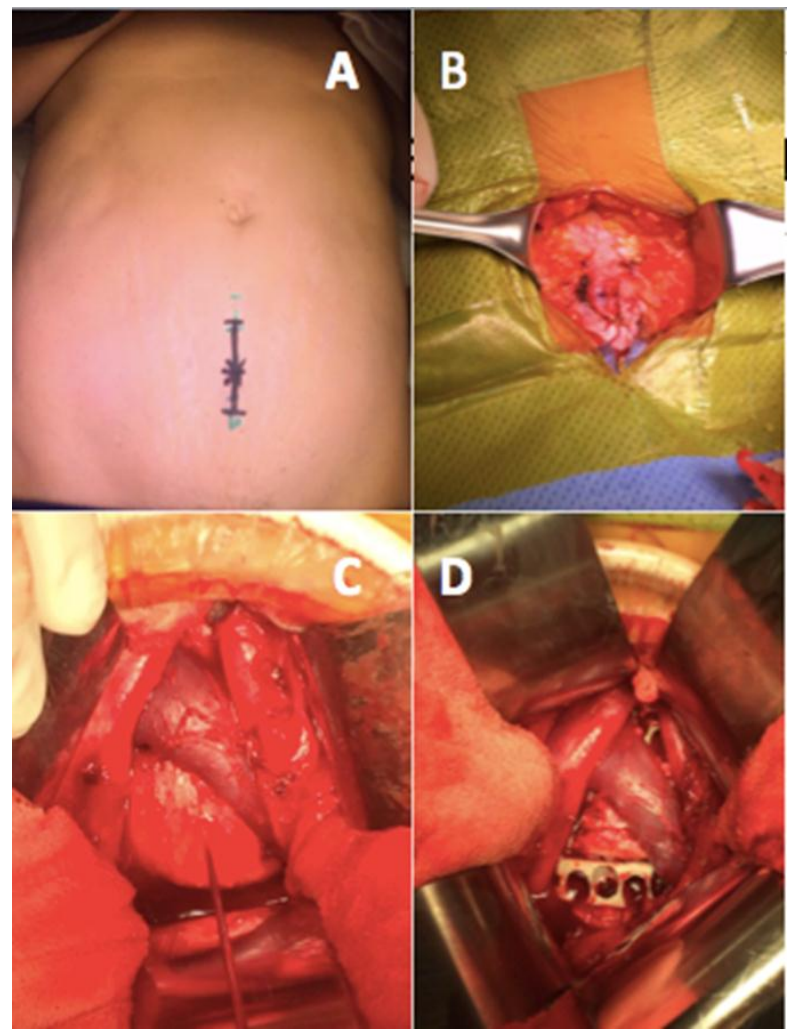

Figure 1: Anterior Lumbar interbody fusion (ALIF) steps: A. infraumbilical middle line $4-5 \mathrm{~cm}$ skin incision is marked, $\mathbf{B}$. Locate anterior aponeurosis, rectus abdominis, mobilized the contents of the abdominal cavity and exposed the lateral landmark the psoas muscle. C. The next lateral landmark to identify of the level L5-S1 is the iliac vessels, the discectomy is later performed. D. Finally the stand alone lordotic cage is placed in the worked space.

\section{Results}

\section{Patient population}

The number of patients was 20; 16 females $(80 \%)$ and 4 males (20\%) with a follow-up 36 months, the mean age of the studied group was 50.1 \pm 8.5years (range 35-67 years), body mass index (BMI) was $29 \pm 3.5$.

\section{Operative details}

Two of the 20 patients (10\%) had undergone prior spine surgery, a total of 26 ALIF levels were treated in 20 patients, fourteen patients $(70 \%)$ underwent 1 level L5-S1 ALIF and six patients (6\%) underwent 2 level L4-L5,L5-S1-ALIF. All ALIF cages were supplemented with anterior integrated fixation, eight(40\%) of 20 patients were treated with posterior spinal fixation in addition to their ALIF procedure, Twelve (60\%) of 20 patients were standalone ALIF. The mean hospital stay after ALIF procedure were $4.05 \pm 1.87$ days (range 2-9 days).

\section{Radiographic parameters}

PI, SS, PT and LL were measures preoperative and the postoperative was the last reported during the 3 years follow up (Table 1), (Figure 2) provide example of measures of spinopelvic balance and lumbar lordosis, only PI and SS has statistically significant ( $p=0.008$ and 0.012 ) correspondingly. 
Table 1: Radiographic measures in all patients

\begin{tabular}{|l|l|l|l|l|}
\hline Radiographic measures & Preop & Posop & $\boldsymbol{\Delta}^{*}$ & P \\
\hline PI & $56.0 \pm 15.01$ & $60.6 \pm 14.80$ & 4.6 & 0.008 \\
\hline PT & $14.0 \pm 9.47$ & $15.3 \pm 8.45$ & 1.3 & 0.339 \\
\hline SS & $39.5 \pm 11.00$ & $44.8 \pm 8.80$ & 5.3 & 0.012 \\
\hline LL & $58.7 \pm 11.71$ & $61.1 \pm 11.47$ & 2.3 & 0.218 \\
\hline VAS & $8.9 \pm 1.23$ & $3.4 \pm 2.28$ & 5.5 & 0.001 \\
\hline $\begin{array}{l}\text { Mean values are presented as the mean } \pm \text { SD. } \\
* \text { Change from preoperative to postoperative. }\end{array}$ & & \\
\end{tabular}

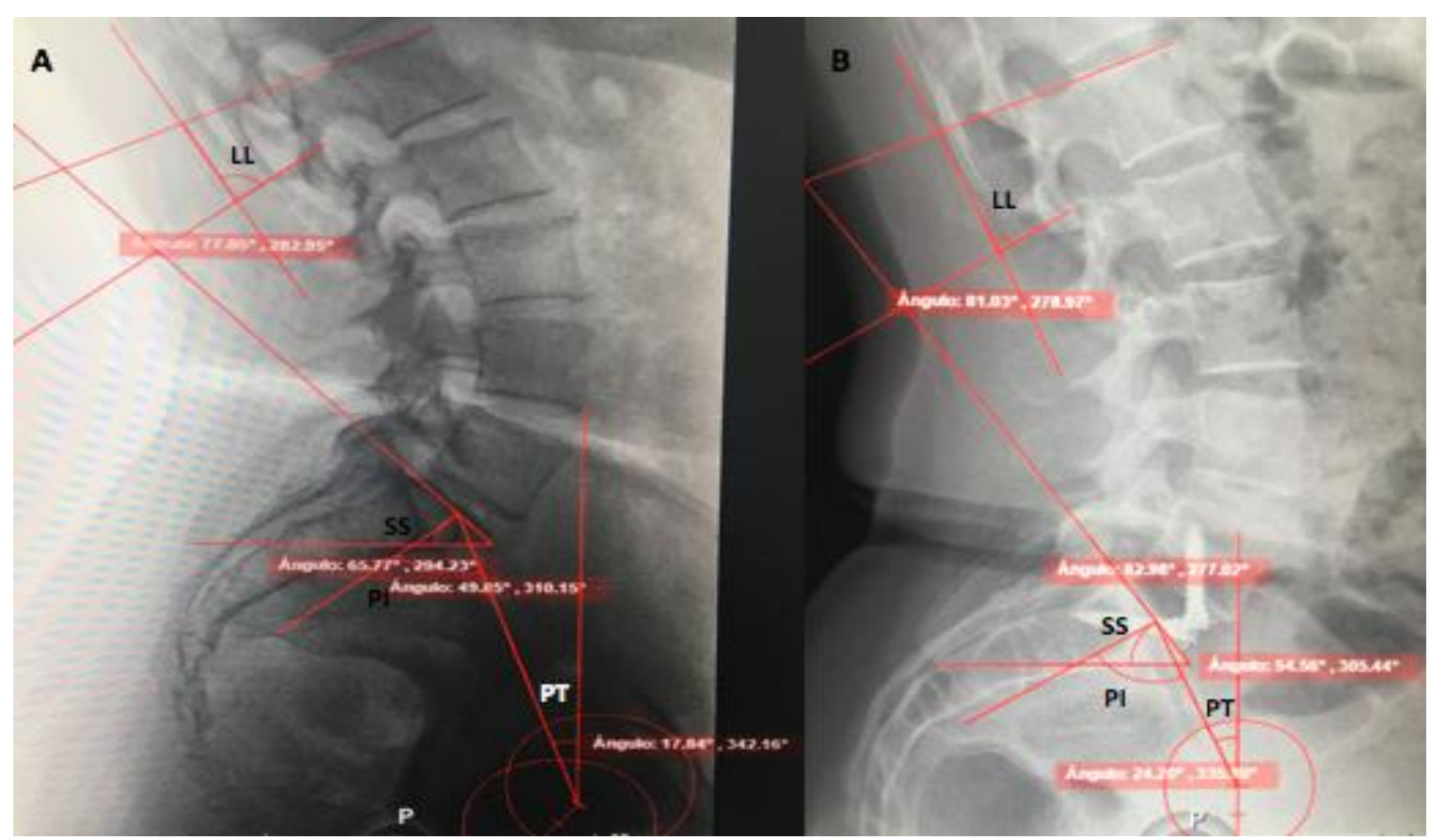

Figure 2: Radiographic measures: spinopelvic parameters, pelvic tilt (PT), sacral slope (SS), pelvic incidence (PI) and lumbar lordosis (LL) A) preoperative parameters in lateral $\mathrm{X}$ ray, B) postoperative parameters in $\mathrm{X}$ ray.

\section{Outcomes measures}

Visual analog scale (VAS) was the measure preoperative and the postoperative was the last reported during the 3 years follow up getting statistically significant $(\mathrm{p}=0.001)$.

\section{Complications}

The complications obtained in 4 cases were persistent pain, bleeding, intestinal pseudoclusion and retrograde ejaculation.

\section{Discussion}

The spine can be studied under a sagittal, coronal and axial plane. The biomechanics of the lumbar spine has been a subject of current discussion of great importance for correction of the coronal and sagittal balance. The appropriate segmental alignment required to get an adequate global balance, the progressively loss of the compensatory mechanisms lead to degenerative lumbar and disc disease, low back pain, deformity and instability that may require surgery ${ }^{[21]}$.

Spinopelvic parameters of importance such as pelvic incidence (PI) are known to vary with age and their value reflects the anatomy of the pelvis, not the values of sacral slope (SS), pelvic incidence (PI) that derive directly from the position of the pelvis. In the same way, the increase in PI after a surgical procedure for degenerative deformity leads to an increase in lumbar lordosis ${ }^{[39,40,41]}$.

It has been observed that the alterations in the PI lead to the isthmic spondylolysis and spondylolisthesis sustained in multiple studies of abnormal spinopelvic balance. In general, the correlations of the study we conducted were based on identifying the modification of spinopelvic parameters found in our population before and after the ALIF intervention, observing similarity to those studied by other authors ${ }^{[1,18,39]}$.

Other studies in the literature reported that the normal range of the pelvic incidence is between 40 to 65 , sacral slope 30 to 50 , the normal range of lumbar lordosis between 31 an 70 which in our study this parameters are within the ranges of world literature ${ }^{[39]}$.

Loss of LL has been shown to be closely related to clinical symptom operative complications such as subsequent intervertebral disc degeneration and cororal and sagittal imbalance ${ }^{[40,41]}$.

In our study, there was a positive correlation between postoperative PI and postoperative lumbar lordosis that is to say that for each increasing degree of the postoperative PI it increases by 54\% the postoperative LL, as it is known in the literature ${ }^{[42]}$. Postoperative pain was also evaluated, presenting an improvement of 5 points between the start of treatment and the last medical visit. A positive clinical correlation with postoperative lumbar lordosis and postoperative pain to ALIF described in (Table 2) as scatter table. However, we observed that the greatest changes in spinopelvic parameters were seen in patients with 2 levels of ALIF L4-L5, L5$\mathrm{S} 1$, whom a modification of the lumbar lordosis was actually observed. (Table 3) 
Table 2: Dispersion of LL and VAS preoperative (A) and postoperative (B)

A

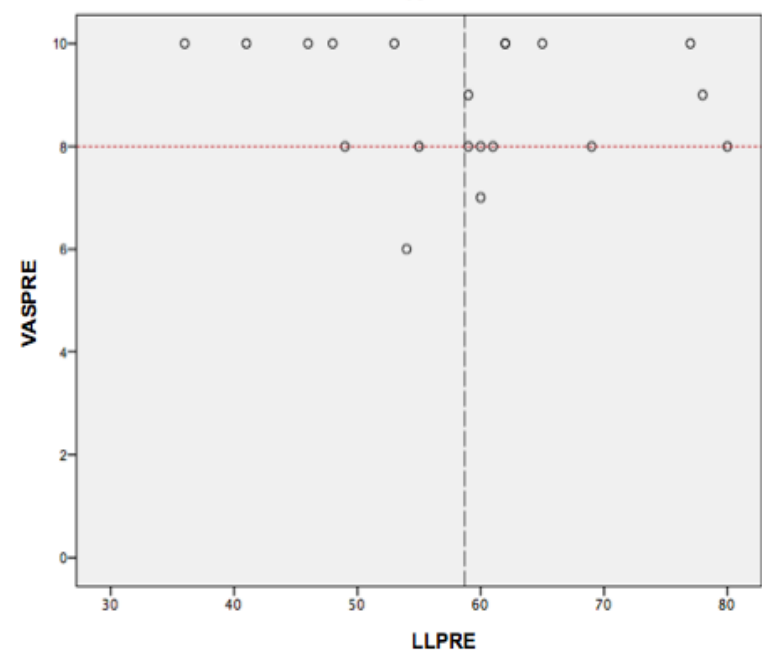

B

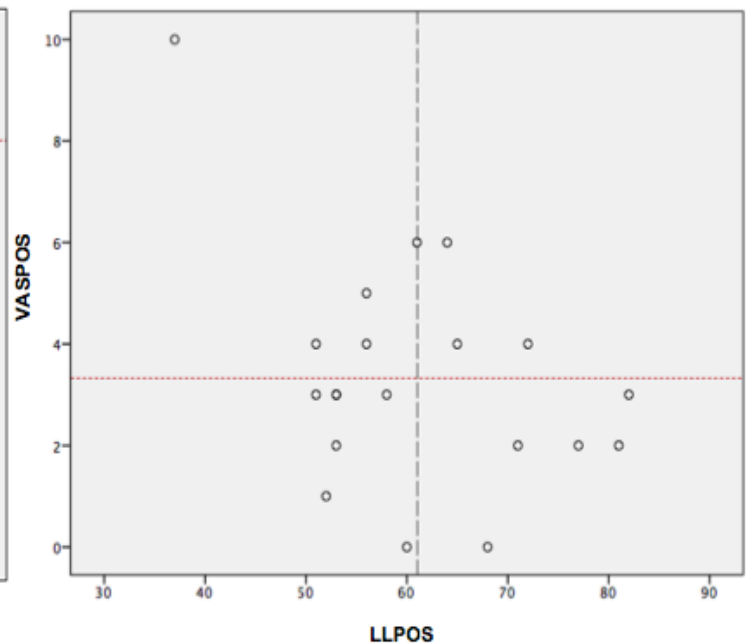

Table 2: A mean $=58.7$ for LL and a mean of 8.85 for VAS was obtained in the preoperative (A), both with changes in the postoperative evaluation of the means; for the LL of 2.35 and for VAS of 5.5).

Table 3: ALIF L5-S1

\begin{tabular}{|l|l|l|l|l|}
\hline Radiographic measures & Preop & Posop & $\Delta^{*}$ & P \\
\hline PI & $59.2 \pm 15.46$ & $62.1 \pm 16.90$ & 2.9 & 0.160 \\
\hline PT & $15.1 \pm 10.08$ & $15.6 \pm 9.59$ & 0.5 & 0.767 \\
\hline SS & $40.5 \pm 12.60$ & $45.6 \pm 9.89$ & 5.1 & 0.078 \\
\hline LL & $61.3 \pm 11.58$ & $61.3 \pm 12.60$ & 0.0 & 1.000 \\
\hline VAS & $8.6 \pm 1.28$ & $3.2 \pm 2.42$ & 5.4 & 0.000 \\
\hline $\begin{array}{l}\text { Mean values are presented as the mean } \pm \text { SD. } \\
* \text { Change from preoperative to postoperative. }\end{array}$ & \\
\end{tabular}

ALIF L4-L5, L5-S1

\begin{tabular}{|l|l|l|l|l|}
\hline Radiographic measures & Preop & Posop & $\Delta^{*}$ & P \\
\hline PI & $48.3 \pm 11.64$ & $57.0 \pm 8.25$ & 8.7 & 0.007 \\
\hline SS & $11.3 \pm 8.02$ & $14.3 \pm 5.54$ & 3.0 & 0.151 \\
\hline LL & $37.0 \pm 6.03$ & $42.8 \pm 5.78$ & 5.8 & 0.022 \\
\hline VAS & $52.7 \pm 10.48$ & $60.5 \pm 9.31$ & 7.8 & 0.051 \\
\hline $\begin{array}{l}\text { Mean values are presented as the mean } \pm \text { SD. } \\
\text { *Change from preoperative to postoperative. }\end{array}$ & $9.3 \pm 1.03$ & 5.7 & 0.002 \\
\hline
\end{tabular}

This study had the following limitations: first this study was limited by its retrospective nature, second the study was a single center study and there were only a limited number of patients, considering that this first trial study on the country and exists a few studies correlating ALIF with spinopelvic balance we suggest making multicenter studies and large simple to get best results.

\section{Conclusions}

The interaction between the anatomy of the pelvis and the paravertebral muscles have a direct influence on the stress of the intervertebral discs, improving the posture of the spine and minimizing energy expenditure.

In this work performed the changes in the espinopelvic parameters that are described in the literature were obtained; We know that the ALIF improves the pelvic incidence and therefore the lumbar lordosis postoperative. Here we could verify that the modification of spinopelvic balances is related to the clinical improvement of the patient in the follow-up after his surgery, however is necessary to demonstrate quantitatively the modification of these parameters in our population to justify that the surgery is a satisfactory result for the patient.

\section{Conflict of interest}

$\underline{\text { www.ijirms.in }}$
The authors report no conflict of interest concerning the materials or methods used in the present study.

\section{References}

[1] Mobbs RJ,Loganathan A, Yeung V, Rao PJ. Indications for anterior lumbar interbody fusion. Orthopaedic Surgery. 2013;5:153-163.

[2] Shen FH, Samartzis D, Khanna AJ, Anderson DG. Minimally invasive techniques for lumbar interbody fusions. Orthop Clin North Am, 2007; 38: 373-386.

[3] Capener N. Spondylolisthesis. Br J Surg, 1932;19: 374386.

[4] Holte D, O'Brien J, Renton P. Anterior lumbar fusion using a hybrid interbody graft. Eur Spine J. 1994; 3: 3238.

[5] Burke PJ. Anterior lumbar interbody fusion. Radiol Technol, 2001; 72: 423-430. 
[6] Lipson SJ. Spinal-fusion surgery-advances and concerns. N Engl J Med, 2004; 350: 643-644.

[7] Fang H, Ong G, Hodgson A. Anterior spinal fusion. Clin Orthop Relat Res, 1964; 35: 16-25.

[8] Truumees E, Majid K, Brkaric M. Anterior lumbar interbody fusion in the treatment of mechanical low back pain. Semin Spine Surg, 2008; 20: 113-125.

[9] Werlinich M. Anterior interbody fusion and stabilization with metal fixation. Int Surg, 1974; 59: 269-273.

[10] Strube P, Hoff E, Hartwig T, Perka CF, Gross C, Putzier M. Stand-alone anterior versus anteroposterior lumbar interbody single-level fusion after a mean follow-up of 41 months. J Spinal Disord Tech, 2012; 25: 362-369.

[11] Kim JS, Kim DH, Lee SH, et al. Comparison study of the instrumented circumferential fusion with instrumented anterior lumbar interbody fusion as a surgical procedure for adult low-grade isthmic spondylolisthesis. World Neurosurg, 2010; 73: 565-571.

[12] Mummaneni PV, Haid RW, Rodts GE. Lumbar interbody fusion: state-of-the-art technical advances. J Neurosurg Spine, 2004; 1: 24-30.

[13] Gumbs AA, Bloom ND, Bitan FD, Hanan SH. Open anterior approaches for lumbar spine procedures. Am J Surg, 2007; 194: 98-102.

[14] Mummaneni PV, Haid RW, Rodts GE. Lumbar interbody fusion: state of the art technical advances. J Neurosurg Spine, 2004;1: 24-30.

[15] Burkus JK, Gornet MF, Dickman CA, Zdeblick TA. Anterior lumbar interbody fusion using rhBMP-2 with tapered interbody cages. J Spinal Disord Tech, 2002; 15: 337-349.

[16] Chung SK, Lee SH, Lim SR, et al. Comparative study of laparoscopic L5-S1 fusion versus open mini-ALIF, with a minimum 2-year follow-up. Eur Spine J, 2003; 12: 613-617.

[17] Greenough C, Taylor L, Fraser R. Anterior lumbar fusion: results, assessment techniques and prognostic factors. Eur Spine J, 1994; 3: 225-230.

[18] Hosseini P et al. Preliminary results of anterior lumbar interbody fusion, anterior column realignment for the treatment of sagittal malalignment. Neurosurg Focus. 2017; 43:E6

[19] Wang Z, Wang B, Yin B, Liu W, Yang F, Lv G.The relationship between spinopelvic parameters and clinical symptoms of severe isthmic spondylolisthesis: a prospective study of 64 patients. Eur Spine J. 2014; 23:560-568

[20] Lim JK, Kim SM. Degenerative Spondylolisthesis and Isthmic Spondylolisthesis. J Korean Neurosurg Soc. 2013; $53: 96-101$

[21] Mehta VA et al. Implications of Spinopelvic Alignment for the Spine Surgeon. Neurosurgery. 2012; 70:707-721.

[22] Roussouly P, Gollogly S, Berthonnaud E, Labelle H, Weidenbaum M. Sagittal alignment of the spine and pelvis in the presence of L5-s1 isthmic lysis and lowgrade spondylolisthesis. Spine (Phila Pa 1976). 2006; 31(21):2484-2490.

[23] LegayeJ,Duval-

BeaupereG,HecquetJ,MartyC.Pelvicincidence:afundame ntal pelvic parameter for three-dimensional regulation of spinal sagittal curves. Eur Spine J. 1998;7(2):99-103.
[24] Vialle R, Levassor N, Rillardon L, Templier A, Skalli W, Guigui P. Radiographic analysis of the sagittal alignment and balance of the spine in asymptomatic subjects. J Bone Joint Surg Am. 2005; 87(2):260-267.

[25] Lazennec JY, Ramare S, Arafati N, et al. Sagittal alignment in lumbosacral fusion: relations between radiological parameters and pain. Eur Spine J. 2000; 9(1):47-55.

[26] Jang JS, Lee SH, Min JH, Maeng DH. Changes in sagittal alignment after restoration of lower lumbar lordosis in patients with degenerative flat back syndrome. J Neurosurg Spine. 2007;7(4):387-392.

[27] Barrey C, Jund J, Perrin G, Roussouly P. Spinopelvic alignment of patients with degenerative spondylolisthesis. Neurosurgery. 2007; 61(5):981-986; discussion 986.

[28] Barrey C, Jund J, Noseda O, Roussouly P. Sagittal balance of the pelvis-spine complex and lumbar degenerative diseases: a comparative study about 85 cases. Eur Spine J. 2007;16(9):1459-1467.

[29] Kumar MN, Baklanov A, Chopin D. Correlation between sagittal plane changes and adjacent segment degeneration following lumbar spine fusion. Eur Spine J. 2001;10(4):314-319.

[30] Marty C, Boisaubert B, Descamps H, et al. The sagittal anatomy of the sacrum among young adults, infants, and spondylolisthesis patients. Eur Spine J. 2002;11 (2):119-125.

[31] Mac-Thiong JM, Labelle H, Berthonnaud E, Betz RR, Roussouly P. Sagittal spinopelvic balance in normal children and adolescents. Eur Spine J. 2007;16(2): 227 234.

[32] Oh YM, Eun JP. Clinical Impact of Sagittal Spinopelvic Parameters on Disc Degeneration in Young Adults. Medicine.2015; 94(42):e1833.

[33] Chaléat-Valayer E, Mac-Thiong JM, Paquet $J$ et al: Sagittal spino-pelvic align- ment in chronic low back pain. Eur Spine J. 2011; 20 (Suppl. 5): 634-40.

[34] 33.-Ploumis A, Liu H, Mehbod AA et al: A correlation of radiographic and func- tional measurements in adult degenerative scoliosis. Spine (Phila Pa 1976), 2009; 34: 1581-84.

[35] Zou HB, Wu CH, Mehbod AA et al: Prediction of health status based on postoperative radiographic variables in adult scoliosis. Orthop Surg. 2014; 6: 196-202.

[36] Trobisch PD, Samdani AF, Betz RR et al: Analysis of risk factors for loss of lumbar lordosis in patients who had surgical treatment with segmental instrumentation for adolescent idiopathic scoliosis. Eur Spine J. 2013; 22: 1312-16.

[37] Cho KJ, Suk SI, Park SR et al: Arthrodesis to L5 versus S1 in long instrumen- tation and fusion for degenerative lumbar scoliosis. Eur Spine J. 2009; 18: 531-37.

[38] Lee JH, Kim KT, Lee SH et al: Overcorrection of lumbar lordosis for adult spinal deformity with sagittal imbalance: Comparison of radiographic out- comes between overcorrection and undercorrection. Eur Spine J. 2016; 25: 2668-75.

[39] Gao X. Predictors for postoperative loss of lumbar lordosis after long fusions arthrodesis in patients with adult scoliosis. Med Sci Monit. 2018;24: 531-538. 
[40] Rao PJ, Loganathan A, Yeung V, Mobbs RJ. Outcomes of Anterior Lumbar Interbody Fusion Surgery Based on Indication: A Prospective Study. Neurosurgery. 2015; 76:7-24.

[41] Nunes VR et al. Spinopelvic balance evaluation of patients with degenerative spondylolisthesis L4L5 and L4L5 herniated disc who underwent surgery. REV BRAS ORTOP. 2016;51(6):662-666.
[42] Schwab FJ et al. Radiographical Spinopelvic Parameters and Disability in the Setting of Adult Spinal Deformity. Spine 2013;38:E803-E812.

[43] Lee, JH., Na, KH., Kim, JH. et al. Is pelvic incidence a constant, as everyone knows? Changes of pelvic incidence in surgically corrected adult sagittal deformity. Eur Spine J. 2016;25: 3707-3714. 